\title{
Dinâmica Industrial e Inovação no Estado do Paraná entre 2004 e 2014
}

Greice Morais Dalla Corte greice.dc@hotmail.com

Universidade Estadual do Oeste do Paraná (UNIOESTE), Francisco Beltrão Paraná, Brasil

\section{Marcelo Lopes de Moraes}

\author{
RESUMO
}

No processo de crescimento e desenvolvimento econômico, a participação do setor secundário, e seu respectivo nível de produtividade, apresenta papel relevante. Nesse contexto, o objetivo deste trabalho foi analisar os índices de produtividade e verificar o desempenho da dinâmica da indústria paranaense. A metodologia empregada consistiu no cálculo dos índices de produção e produtividade industrial, no período de 2004 a 2014, e na comparação de tais indicadores com o nível nacional a luz dos teóricos sobre inovação e produtividade. Os resultados apontaram que o adensamento industrial se mostra com perspectiva de queda, a composição setorial está pautada na indústria de alimentos e que o valor da transformação industrial como proporção do PIB está acima da média nacional, porém com intenso uso de mão de obra. Destaca-se também que a baixa especialização do Capital Humano resulta em um ambiente estadual com baixa propensão a inovar e, consequentemente, baixa produtividade. Sugere-se que os elementos determinantes de inovação e produtividade não estão sendo potencialmente utilizados para atingir maiores taxas de crescimento econômico no Paraná.
\end{abstract}

PALAVRAS-CHAVE: Produtividade. Inovação. Paraná. 


\section{INTRODUÇÃO}

Um dos grandes questionamentos dos economistas na atualidade é a questão da disparidade do desenvolvimento econômico entre os países. Por que alguns países conseguem chegar a um alto nível de desenvolvimento e de qualidade de vida, enquanto outros ainda apresentam indicadores de baixo desenvolvimento? A literatura trata a produtividade como elemento central para responder esta questão. O economista e ganhador do Prêmio Nobel de Economia em 2008, Paul Krugman em 1994 afirmou: "A produtividade não é tudo, mas no longo prazo é quase tudo".

E um dos fatores propulsores da produtividade é a inovação, a qual se baseia no progresso tecnológico para tornar a alocação dos fatores de produção mais eficiente. A inovação, por sua vez, é abordada por Schumpeter como variável central para o desenvolvimento econômico, e a discussão se consolida por pensadores que seguem sua teoria, chamados de neoschumpeterianos. No entanto, no decorrer de avanços teóricos baseados em pesquisas empíricas, são identificadas outras variáveis que que determinam a capacidade de inovar e, como consequência, afetam a produtividade, tais como a Pesquisa e Desenvolvimento (P\&D), capital humano, tecnologias, etc.

O sentido de estudar a produtividade é compreender meios pelos quais é possível melhorar a qualidade de vida da população. Neste contexto, busca-se conhecer mais atentamente a relação inovação e produtividade, e identifica-se que o capital humano tem sido amplamente aceito como fomentador desta relação. Verifica-se também, que estas variáveis têm sido exploradas ao máximo por países desenvolvidos, tanto que a institucionalização da P\&D mudou o cenário de concorrência, estimulando a especialização, a obtenção de vantagens de custo e a globalização. Apesar da complexidade da discussão, o capital humano pode ser visto como elemento propulsor de crescimento pela contribuição que dá as demais variáveis fundamentais a ele. Os esforços direcionados para uma boa educação é considerado algo possível de ser oferecido por qualquer nação. A inovação tecnológica tem a capacidade de tornar a economia continuamente dinâmica, incerta e desafiadora. Os desafios impostos por ela proporcionam o desencadeamento de um complexo sistema interativo dos aspectos sociais, econômicos, tecnológicos e científicos, cujas organizações industriais buscam sempre estar conectadas (DOSI, 2006; FREEMAN e SOETE, 2008; PORTER, 1989).

Com uma visão voltada aos países em desenvolvimento, Kim (2005) ressalta a importância de recuperar o atraso e obter crescimento produtivo. Para isso é necessário administrar corretamente a P\&D e buscar efetividade entre oferta e demanda, fatores que dependem da obtenção de aptidão tecnológica combinadas com aptidões comerciais. O Brasil, embora seja uma das maiores economias do mundo, ainda se caracteriza como um país em desenvolvimento. Neste sentido, verifica-se a pertinência da análise da produtividade como um fator que pode impulsionar o desenvolvimento do país. Além do mais, cada estado da federação constitui uma parcela significativa da riqueza nacional. Nesta perspectiva, dados da Federação das Indústrias do Estado do Paraná (FIEP, 2016), indicam que o PIB industrial paranaense é o quarto maior do Brasil. O Estado possui também grande representatividade nacional para as exportações, população, educação, dentre outros aspectos. Identifica-se na sua história a 
constante preocupação com a industrialização no Estado, através de governos empenhados em buscar recursos para a consolidação deste objetivo. Verifica-se ainda, que sua localização é utilizada como estratégia na busca destes recursos, funcionado como um "corredor" que interliga os demais Estados do Sul e também o Brasil com a América do Sul.

Diante deste contexto, o objetivo deste trabalho é analisar os índices de produtividade e verificar o desempenho da dinâmica da indústria paranaense, no período que se entende entre 2004 a 2014. Ou seja, serão calculados indicadores de produtividade do setor industrial brasileiro e paranaense, possibilitando a comparação entre estes. A pesquisa visa contribuir para a literatura, e para eventuais políticas públicas, ao relacionar algumas variáveis, tais como produtividade, evolução de custos, nível de educação, número de pessoal ocupado na indústria, entre outras, e seus possíveis impactos sobre o comportamento da dinâmica industrial paranaense ao longo do período. Além disso, avalia se o comportamento de tais variáveis é compatível com os indicados pela literatura para promover a inovação, produtividade e competitividade, e consequentemente, o desenvolvimento econômico

Segundo o Ipardes (2017) o estado do Paraná possui boa integração com a economia nacional, e possui participação de aproximadamente $6 \%$ do PIB brasileiro. Mais especificamente, o setor industrial, o qual contou com variados incentivos ao longo de sua consolidação, possui uma localização privilegiada que facilita a integração com o comércio exterior, e oscila entre a quarta e quinta posição entre os maiores PIB industriais do Brasil. Deste modo, supõe-se que o estado possua também uma boa produtividade do setor. Diante da representatividade do estado do Paraná para a economia brasileira, supõe-se que os índices apresentem resultados positivos, que indiquem boas perspectivas de desenvolvimento para o estado. De forma que a dinâmica acompanhe os requisitos de desenvolvimento apontados pela teoria.

A estruturação conta com 7 seções, incluindo esta introdução. Na segunda seção será apresentada a Teoria da Inovação de Schumpeter e dos pensadores da corrente neoschumpeteriana e a relação entre as variáveis inovação e produtividade. Na terceira seção será realizado o resgate da história do desenvolvimento industrial do Paraná, e apresentação do panorama atual. $\mathrm{Na}$ quarta seção, serão apresentados trabalhos empíricos sobre o comportamento da produtividade no Brasil e Paraná. Na quinta seção será discorrido sobre a metodologia a ser empregada, enquanto que na sexta e sétima seção serão discutidos os resultados e considerações finais, respectivamente.

\section{REFERENCIAL TEÓRICO}

\section{A INOVAÇÃO SEGUNDO SCHUMPETER}

A inovação passou a ser abordada na economia como elemento principal para o desenvolvimento econômico por Schumpeter, através da sua obra 'Teoria do Desenvolvimento Econômico', de 1911. Observa-se uma condição da economia em que o agente transformador é o empresário, ao que Costa (2006, p. 6) completa: “O empresário é uma figura que se distingue na sociedade por ser o 
portador de uma energia e capacidade de realizar coisas novas que não estariam presentes de maneira difundida entre a população".

De maneira geral, Schumpeter (1988), embasa sua teoria sob o alicerce de três elementos fundamentais: o empresário, cuja função é ser o agente responsável pelas novas combinações; as "novas combinações" definida pelo autor como: "produzir outras coisas, ou as mesmas coisas com método diferente, significa combinar diferentemente esses materiais e força" (SCHUMPETER, 1988, p. 48); e o terceiro elemento é o crédito. $O$ autor expõe cinco maneiras em que é possível realizar novas combinações: a primeira é a inserção de um novo bem, ou seja, a criação de um produto que até então era inexistente; a segunda é a elaboração de uma nova técnica, ou seja, a utilização de novas combinações antes não pensadas; a terceira seria o começo de novos ramos de mercado, em que caberia o acesso a um mercado que pode já existir ou ser gerado; a quarta é a descoberta de uma nova fonte de matéria-prima; e por último a criação de uma organização constituída por monopólio, que não pode ser tão facilmente alcançada por outros.

O primeiro tipo de inovação, proposto por Schumpeter, de longe é o que causa maior impacto na economia. Um exemplo da atualidade que pode exprimir a ideia do autor é a invenção do computador, que a partir da criação de um novo produto desencadeou a formação de um novo mercado, aliás, muito mais complexo. A segunda possibilidade descrita está relacionada à utilização de ferramentas e insumos já existentes, mas que com a utilização de procedimentos diferentes resultam em nova técnica, por exemplo, em novos produtos ou maior agilidade na produção. A terceira opção, apresentada por Schumpeter, dá a ideia da derivação de mercados já existentes, e que por motivos de expansão cria a possibilidade de especialização, exemplificando, cria um novo espaço de investimento para novos empresários atuarem, que pode servir como apoio para a indústria. No caso da descoberta de nova fonte de matéria-prima, o autor admite a importância dos recursos naturais, em que pode surgir como nova opção de insumo para a produção. E finalmente, Schumpeter define o monopólio como resultado da inovação, neste caso há um privilégio de quem detém este poder, porque não há nenhum bem que se iguale a tal produto, e que dá ao empresário poder de extrair lucros bem acima do esperado.

Sendo assim, o desenvolvimento funciona como "ondas" descontínuas na economia, em que combinações antigas são substituídas por novas, levadas pela concorrência, pela quebra do equilíbrio, que gera novamente descontinuidade, e assim sucessivamente (SCHUMPETER, 1988).

Entretanto, embora Schumpeter tenha iniciado as discussões sobre o papel da inovação na economia, o tema foi aprofundado por autores conhecidos atualmente como neoschumpeterianos. Dentre eles, Freeman e Soete (2008) descreveram que atualmente o foco de inovação está na geração e disseminação de informações, sendo a P\&D a principal condução a inovar. Os frutos de P\&D possuem alta proporção de contribuição para o avanço econômico, sendo uma das principais fontes para que ele ocorra. Porém, os autores frisam que para que o P\&D tenha contribuição efetiva, a economia deve agir como um conjunto interativo entre produção industrial, as várias indústrias de conhecimento e o marketing. 
Dosi (2006) frisa sete pontos em que a inovação pode ser estabelecida: ascendência do papel dos insumos científicos; a combinação complexa entre P\&D e desenvolvimento; a correlação entre $P \& D$ e produtos de inovação; relação entre inovação e aperfeiçoamento; a institucionalização formal do P\&D promove um ambiente de incertezas; o engrandecimento da inovação por meio do tempo; e finalmente, o aperfeiçoamento e alcance do nível tecnológico como barreiras à mudança técnica.

A partir das discussões apresentadas pelos autores, a inovação apresenta-se como elemento capaz de tornar a economia constantemente dinâmica, incerta e a certo ponto, desafiadora. Os desafios impostos por ela proporcionam o desencadeamento de um complexo sistema interativo dos aspectos sociais, econômicos, tecnológicos e científicos, cujas organizações industriais se esforçam para estar sempre conectadas a esses ambientes. Tal esforço justifica-se pelo fato de que o incremento da produtividade é uma variável condicionada à inovação, e essa relação será aprofundada na próxima seção.

\section{INOVAÇÃO E PRODUTIVIDADE}

Ainda de acordo com a contribuição de Schumpeter (1988), as inovações têm como objetivo principal reduzir os custos e aumentar a diferença entre preços e custos da mercadoria, ampliando o lucro. Dosi (2006) completa o raciocínio schumpeteriano ao reiterar que o setor industrial só implementa inovações quando há expectativa de retorno, ou quando há prenúncio de perdas de vantagens frente a concorrência. Ademais, o autor reflete que os diferentes recursos e habilidades, tanto na produção quanto na comercialização, geram assimetrias com inclinação à formação de oligopólios e vantagens de custos concebidos pelo "efeito aprendizado".

Numa visão macroeconômica, visando as políticas públicas, Kim (2005) afirma que os países que desejam recuperar o atraso, para obter o crescimento produtivo, devem administrar corretamente $O P \& D$ e buscar efetividade entre oferta e demanda, o que depende da obtenção de aptidões tecnológicas combinadas com aptidões comerciais adequadas. A competência tecnológica, segundo Nelson (2006) deve ser lembrada, uma vez que nem todas as empresas tem aptidão para incorporar rapidamente novas tecnologias, e que o atraso à imitação oportuniza lucros ao inovador. O autor justifica que, dependendo da amplitude e durabilidade desta dispersão, há credibilidade da aceitação desta variável como elemento do processo de aumento da produtividade.

Por outro lado, constata-se que as inserções das inovações concedem à empresa a obtenção de vantagens de custos, que podem ser administradas conforme o comportamento do mercado. Dentre as novas combinações, há o desencadeamento da oportunidade de obtenção da vantagem competitiva, através da melhoria em três principais aspectos: mudança da curva de demanda, da curva de custos ou no melhoramento da capacidade de inovação. No entanto, observa-se uma estreita relação entre a inovação de processo e aumento de produtividade, a interação entre os diversos fatores inovativos como P\&D, estruturas organizacionais, marketing, difusão de conhecimento, dentre outros, permitem que as empresas alcancem melhor performance nas suas atividades (OCDE, 2005). Seguindo as ideias de Porter (1989) destacam-se três aspectos fundamentais: mudanças tecnológicas, dotação de fatores comparáveis e 
globalização. Quanto às mudanças tecnológicas, sua fundamentação dá-se pelo fato de que a tecnologia exclui a influência dos baixos salários e da fartura de recursos, pois é capaz de corrigir estas faltas e falhas através de novos produtos e processos. A dotação de fatores comparáveis quer dizer a formação de infraestrutura básica, mão de obra especializada, dentre outros fatores que atuam como suporte no desenvolvimento de indústrias competitivas, e que está ao alcance da maioria dos países. E finalmente a globalização, em que há a expansão do mercado e da captação de recursos mais qualificados e baratos.

De acordo com Carneiro (2008) o adensamento industrial é uma das estratégias de desenvolvimento econômico. Ao contrário disso, a diversificação pode ser considerada como reveses no mundo globalizado. Isso porque exige a absorção de grandiosa quantidade de capital, dispêndio em aquisições ou desenvolvimento de tecnologias e incompatibiliza a produção em larga escala. Ou seja, a especialização em determinadas atividades permite aumentar os efeitos de aprendizagem, e consequentemente aumenta as possibilidades de inovar.

Verifica-se, ao longo das discussões, que a relação entre inovação e produtividade tem se fortalecido, havendo mudanças significativas na forma de relacioná-las, em que o próprio processo inovativo deixa de ser exclusivamente na produção e incluem-se outras variáveis econômicas capazes de gerar maior eficiência nos resultados desta combinação. Com o intuito de verificar esta relação no cenário industrial paranaense, a próxima seção visa apresentar informações socioeconômicas desse setor no estado.

\section{ASPECTOS INERENTES A INDÚSTRIA PARANAENSE}

De acordo com a FIEP (2016), em 2015 o estado representou o $4^{\circ}$ maior PIB nacional, com participação de mais de $6 \%$ de tudo que é produzido no país. Em relação à indústria, a representatividade é ainda maior, sendo responsável, em média, por $7,5 \%$ da produção industrial, além de possuir bons índices de representatividade nas exportações, comércio e serviços, agropecuária, dentre outros indicadores essenciais para o crescimento econômico.

Segundo dados do Instituto Brasileiro de Geografia e Estatística (IBGE) a indústria paranaense absorveu mais mão de obra no período de 2007 a 2014 . Ou seja, tornou-se mais intensiva no uso do fator trabalho na produção. De acordo com a FIEP (2016), a variação de empregos da indústria cresceu em média $31 \%$. Corroborando as informações das duas instituições anteriores, dados do Instituto Paranaense de Desenvolvimento Econômico e Social (IPARDES, 2010) justificam o aumento da absorção de mão de obra apontando que isso ocorreu nos setores cuja produtividade tende a ser baixa, tais como indústrias alimentícias, de vestuário e produtos de metal. Entretanto, o aumento do pessoal ocupado no setor acarretou no declínio da produtividade industrial, ao qual a causa negativa é o achatamento dos salários, que no ciclo 2000-2009 tornou-se o mais baixo entre as regiões sul e sudeste do Brasil.

Diante desta realidade, dados do IBGE (2016) apontam que a média dos salários da indústria de transformação no Paraná são de 2,8 salários mínimos entre os anos de 2010 e 2014, abaixo da média nacional que são de 3,2 salários mínimos. Ainda assim, a taxa de variação dos salários industriais teve um 
aumento acima da média nacional, chegando nos últimos anos a ser maior, influenciando a questão de custos ao qual será tratado adiante.

Uma das questões que geralmente levantam discussões quanto aos salários é a especialização dos recursos humanos. Teoricamente um alto grau de instrução causa elevação do nível salarial. Os dados do IBGE referentes à escolaridade apontam que $6 \%$ da população brasileira com nível superior no ano 2000 estavam no Paraná, essa relação aumenta em 2010 para 6,45\%. Segundo o Ministério de Ciência, Tecnologia e Informação (MCTI, 2016) no Brasil, em 2000, cerca de $29 \%$ dos ingressantes concluíam o curso de graduação, em 2013 essa relação média chega a $37 \%$, enquanto que no Paraná a conclusão era menos de $20 \%$ dos ingressantes.

O panorama de educação da FIEP (2016) completa destacando que 9,7\% da população total do estado possui ensino superior completo, e apenas a metade da população com idade apta, possui ensino médio completo, além disso, os anos de estudo da população paranaense está fixada em torno de 7,55 anos. Comparado a nível de Brasil de 7,18 anos, o estado mantém uma média distinta, mas fica abaixo de alguns estados como São Paulo, Rio de Janeiro, Santa Catarina e Amapá, que apresentam respectivamente, 8.16, 8.2, 7.8 e 7.7 anos de estudos, sem contar com os dados do Distrito Federal que mantém a média de 9 anos de estudo. Em contrapartida, a taxa de analfabetismo é uma das mais baixas do país, equivalendo a $5,8 \%$ da população. A baixa média de população formada em ensino superior e poucos anos de estudo refletem em outro fator de relevância para o incremento de índices de inovação e produtividade, o P\&D.

De acordo com dados do MCTI (2016), os gastos despendidos em P\&D no Estado, em termos percentuais, ficam abaixo de $2 \%$ do PIB. Ou seja, inferior comparado às economias mais desenvolvidas, menos da metade do investimento realizado pelo estado de São Paulo, que é em média 4,5\% do PIB. Vale ressaltar que mais de $69 \%$ dos gastos considerados em P\&D são destinados ao ensino superior, sendo o restante dividido em $20 \%$ para pesquisas não orientadas, quase $6 \%$ para a agricultura, cabendo ao desenvolvimento industrial apenas $2,7 \%$ dos recursos. O setor público é responsável pela maior participação nestes gastos.

Dados do IPARDES (2017), apontam que houve crescimento da infraestrutura técnico-cientifica no Paraná entre 2003 e 2015. No entanto, a concentração é um problema recorrente, isso porque se verificou que a base técnico-científica acompanha relativamente a atividade econômica. Ou seja, as regiões que possuem maior atividade econômica são aquelas que têm condições de desenvolver meios de articular projetos cooperativos e envolver instituições. Além disso, são as localidades que possuem maior facilidade em conseguir apoio e captar recurso federal e também internacional.

De acordo com o IPARDES (2010), o Paraná tem uma característica muito singular do gerenciamento da Ciência e Tecnologia (C\&T) por duas instituições, a Fundo de Amparo à Pesquisa (FAPs) e a Fundação Araucária, esta última de caráter privado. Assim sendo, os registros de patentes indicam que o estado do Paraná tem desenvolvido poucas inovações. Ainda assim, o estado está entre os quatro que mais registram patentes no país, com uma representatividade média de 9\%, abaixo de São Paulo que registra 4 vezes mais patentes, com representatividade média a nível de Brasil de 37\% (MCTI, 2016). 
Segundo o MCTI (2016), São Paulo é o estado que mais registra patentes no Brasil, seguido de Minas Gerais, Rio Grande do Sul, Paraná, Santa Catarina e Rio de Janeiro, respectivamente. Pode-se entender que isso ocorre devido aos investimentos despendidos em P\&D, no entanto, verifica-se que os gastos de São Paulo são quatro vezes maiores em relação a estes estados, e isso pode ser explicado, primeiramente, pela presença de grandes universidades em conjunto com o alto desenvolvimento industrial paulista. Quanto ao Paraná entende-se que os dados estão coerentes com a importância paranaense na proporção de industrialização para o país.

São Paulo, Santa Catarina, Minas Gerais, Paraná e Rio Grande do Sul são os cinco estados que gerenciavam cerca de $50 \%$ das pesquisas do Brasil, consequentemente com o maior número de pesquisadores. No caso paranaense, isto tornou-se possível devido ao revigoramento das Instituições Estaduais de Ensino Superior (IEES), que a partir de 2004 recebeu atenção do governo estadual com recursos para a modernização dos equipamentos (IPARDES, 2010).

O fator custos é outro indicador que merece ser destacado, pois retrata a realidade do desenvolvimento industrial, a maturidade do complexo e melhora a competitividade. Verifica-se que o crescimento dos custos operacionais no estado do Paraná tem aumentado mais do que a variação a nível de Brasil, sendo que a superação ocorre a partir de 2011 (IBGE, 2016). Segundo a FIEP (2016), as variáveis que mais contribuíram para o aumento dos custos são as de energia e pessoal, nos dados apresentados pela instituição, verifica-se o custo com folha de pagamento vem crescendo acima da produção física. Somente no ano de 2013, a variação dos custos foi em média $66 \%$, enquanto que a produção variou em média cerca de $20 \%$.

Castagna et al. (2016) aponta o setor energético paranaense em crise, que se deve ao crescimento desenfreado do consumo devido ao expressivo aumento da população urbana em conjunto com a falta de planejamento, seguindo a tendência nacional. O Paraná conta com importantes usinas hidrelétricas, entre elas a Itaipu que é a segunda maior do mundo e produz energia hídrica, consistindo em energia renovável e limpa. O Brasil é considerado o maior produtor deste tipo de energia, com cerca de $48 \%$ do consumo, nível alto comparando com países europeus que contam com apenas $13 \%$ deste tipo de energia.

No Paraná, a indústria consome cerca de $42 \%$ do total de energia produzida, sendo evidente que as regiões urbanizadas e industrializadas são as que mais consomem. É difícil pensar em desenvolvimento ou crescimento econômico sem o uso de energia, tanto que eles apontam que o estado possui um grande potencial para a geração de energia solar devido às características climáticas. Por fim, sendo assim, é imprescindível investimentos neste setor tanto para redução dos custos quanto para a garantia de crescimento (CASTAGNA et al., 2016).

De maneira geral, o que se verifica no contexto da industrialização do estado do Paraná é uma formação pautada em etapas, quase sempre acompanhando as políticas da economia nacional. 0 governo estadual, por sua vez, desempenhou papel fundamental, tanto ao adotar políticas de incentivos à instalação de indústrias em território paranaense, quanto na construção de infraestrutura básica necessária ao suporte de um parque industrial. Ao longo dos anos, visualiza-se o crescente desenvolvimento industrial. Parte de indústrias 
madeireiras começam a fornecer espaço ás agroindústrias, depois aos produtos de base até chegar ao desenvolvimento de indústrias com níveis de alta tecnologia. Contudo, os dados demonstram que, nos últimos anos, há uma tendência geral de queda da produção industrial, principalmente de produtos com uso maior de tecnologias produtivas, enquanto que as indústrias de produtos primários, como de madeiras, demonstram uma elevação de produção. Ou seja, os dados indicam uma tendência de inversão de produção dos segmentos industriais (OLIVEIRA, 2001; MIGLIORINI, 2006; MACEDO, 2009).

Em equivalência com os dados observa-se concentração de recursos, de população, infraestrutura e outros indicadores, que conforme apresentados pelo IPARDES (2006), constituem barreiras para a homogeneização do desenvolvimento. No entanto, esta mesma instituição reconhece que este problema não é um problema exclusivo do estado, nem mesmo do Brasil que também apresenta heterogeneidade em vários aspectos. Todavia, examina-se que grande parte dos dados apontam queda dos fatores que impulsionam o desenvolvimento econômico, principalmente o capital humano.

\section{LITERATURA RECENTE}

Será apresentada nesta seção uma revisão dos trabalhos da literatura sobre o tema desta pesquisa. Dada a limitação de pesquisas voltadas especificamente para o estado paranaense, será realizada uma abordagem que parte de evidências a nível de Brasil para, posteriormente, abordar as repercussões da literatura para o Paraná.

No Brasil, verifica-se heterogeneidade tanto da distribuição industrial por regiões, em que alguns estados despendem investimentos maiores em indústrias mais ou menos produtivas, quanto nos setores dentro de cada estado, em que há oscilação da produtividade em determinados períodos e setores (PINHEIRO e BARBOSA FILHO, 2011; GALEANO e WANDERLEY, 2013).

$\mathrm{Na}$ pesquisa desenvolvida por Galeano e Wanderley (2013), a produtividade a nível nacional manteve-se constante dentro do período estudado, 1996 a 2007. As principais conclusões indicaram que a abertura comercial afeta a economia tanto positiva quanto negativamente, e as mudanças tecnológicas são as chaves que conduzem a economia na obtenção dos efeitos positivos. No entanto, os autores perceberam que não ocorreram mudanças significativas nestas estruturas essenciais de tecnologia.

Arbache (2005) investigou se entre o período de 1997 a 2001, as inovações tecnológicas e as exportações afetaram a produtividade das firmas manufatureiras brasileiras. $\mathrm{O}$ autor utilizou dados como: valor da transformação industrial (VTI), receita total e pessoal ocupado para avaliar o desempenho das firmas; para analisar os trabalhadores foram utilizados dados como: salário médio, escolaridade média e tempo médio de emprego; e finalmente para avaliar as inovações, foram utilizados os dados de inovação de produto novo para o mercado e dispêndio das firmas com o P\&D. Os resultados obtidos indicam que há correlação entre inovações, exportações e desempenho das firmas, segundo os efeitos desencadeados a economia brasileira é afetada pelo impulso da tecnologia. 
Santos (2012) teve como objetivo discutir a capacidade de inovar das empresas brasileiras, a partir do modelo de Índice Brasil de Inovação (IBI), identificar e compreender em que atividades foram concentradas os esforços em inovação e verificar qual a estrutura da inovação frente à dimensão destas empresas. Utilizou da análise descritiva e cálculos de índices voltados aos aspectos de rentabilidade, qualificação profissional e atividade inovativa, entre outros. Os dados utilizados foram extraídos da pesquisa de Inovação PINTEC, do IBGE. Os principais resultados apontaram que a inovação não é tida pelas empresas como uma estratégia a longo prazo e que há heterogeneidade nos esforços empregados em inovação entre as empresas. Além disso, constatou-se que a principal atividade inovativa das empresas brasileiras é a aquisição de máquinas, seguido de baixo investimento em P\&D na criação de produtos que proporcionam mudanças radicais e baixa participação interna de profissionais voltados à pesquisa.

Nassif (2008) utilizou dados industriais para analisar se ocorreu desindustrialização no Brasil, e para isto calculou índices de produtividade do trabalho para verificar o comportamento intrínseco da produção nacional. 0 período analisado pelo autor vai desde os anos 1980 e se estende até 2005 . Com o uso de diferentes metodologias aceitas e utilizadas na literatura econômica, o autor utiliza diversos dados como VTI, PO e Valor Adicionado (VA). O primeiro resultado, cuja metodologia se dá pela razão entre a produção física e pessoal ocupada, demonstra que, até os anos 1990, a produtividade industrial do trabalho, a nível nacional, apresenta evidentes quedas, havendo um exponencial aumento até o final desta década. No entanto, ao avançar nos anos 2000, o crescimento da produtividade acontece em ritmo abaixo à década anterior, com taxa de variação negativa. Na segunda metodologia empregada, cuja razão é entre o VA e PO, há sinalização de queda acentuada da produtividade, com média de variação em torno de $-2,6 \%$. Com intuito de verificar se o deflator corroborou em algum ponto os resultados, o autor dividiu os dados das indústrias de bens de capital das indústrias de transformação, e analisou os resultados, confirmando, assim, que o comportamento da produtividade se confirmou na tendência de decrescimento.

Silva e De Avellar (2015) utilizam do modelo econométrico CDM com o objetivo de analisar o impacto do esforço despendido para inovar sobre a inovação, e dos impactos da inovação sobre a produtividade das empresas. Para os autores as variáveis selecionadas para este estudo são bem completas, na sua grande maioria disponibilizadas pelo IBGE, dados da Pesquisa de Inovação (PINTEC, 2011), como inovação de processo, de produto, gastos com P\&D, e também de fatores de produção que envolve: PO, Valor do Capital por trabalhador, VTI, Produtividade do trabalho, entre outros. O período do estudo analisado foi de 2009 a 2011. Os resultados obtidos pelos autores indicam, a nível nacional, que poucas empresas inovam, e menos de $17 \%$ das empresas brasileiras aplica investimentos frequentes em P\&D. Dentre as que investem em pesquisas, cerca de $20 \%$ utilizam recursos governamentais. Quanto aos impactos sobre a produtividade, as principais respostas apontam que as empresas nacionais que aderem à inovação de produto possuem em média mais de $100 \%$ de crescimento de produtividade, enquanto inovações de processos demonstram redução da produtividade. Como era esperado, quanto maior os gastos em $P \& D$, maior é a possibilidade de ocorrer inovação. 
Em outro contexto, Bender Filho (2014) pesquisou sobre a hipótese de desindustrialização nos estados do Sudeste e Sul do Brasil, comparando com o contexto nacional, no período de 1996 a 2010. Utilizou de um conjunto de indicadores que mediram o adensamento industrial, produtividade da indústria, participação relativa da indústria, valor da transformação industrial como proporção do produto agregado do estado e valor da transformação industrial do estado como proporção do valor de transformação industrial nacional. Os principais resultados apontam que a região sul possui uma maior especialização em indústrias de média-baixa e baixa intensidade tecnológica, enquanto que a região sudeste se especializou em indústrias de média-alta e alta intensidade tecnológica. Além disso, os autores puderam perceber que a região sul desenvolveu tendência de crescimento de indústrias de média-alta e alta intensidade tecnológica.

Em relação ao estado do Paraná Suzuki Júnior (2010) analisou, de forma geral, o crescimento da indústria paranaense. Utilizando dados como VTI e Pessoal Ocupado (PO) na indústria nos anos de 1996 a 2007, o objetivo foi de qualificar o crescimento da economia estadual no período analisado, verificou que a produtividade por trabalhador apresentou decadência conjuntural no período. Nem mesmo os setores com alta produtividade, como o setor automobilístico e petroquímico, foram suficientes para deter a considerável queda desta variável em relação aos anos 90 , que seguiu a tendência nacional.

Rigitano, Nascimento e Camara (2013) verificaram as diferenças na produção e na produtividade da indústria entre as regiões e os setores do Paraná, com objetivo de identificar se existia diferenças na produtividade, relação positiva entre produção industrial e produtividade, e se há setores que demonstraram avanços superiores ao demais em termos de produtividade. A metodologia utilizada foi o modelo econométrico algoritmo de estimação de Levinsonh e Petrin (LP), com variáveis básicas indicativas de produtividade como: VTI, PO, valor total de ativo da empresa e consumo de matérias-primas. O período de análise foi de 2000 a 2006. Os resultados apontaram que houve queda da produtividade média, que setores com maiores produtividades dispunham de maior participação na produção regional. As regiões RMC, Centro Oriental Paranaense e Oeste apresentaram, respectivamente, as maiores médias de Produtividade Total dos Fatores (PTF).

Esta pesquisa visa contribuir para a literatura pertinente ao analisar os níveis de produtividade, composição setorial, densidade e participação percentual do VTI no PIB, do setor industrial do Paraná, entre 2004 e 2014. Para que essa contribuição seja válida, os procedimentos metodológicos têm que ser adequados para alcançar o objetivo proposto. Deste modo, a próxima seção apresenta a metodologia empregada neste estudo.

\section{METODOLOGIA}

A metodologia empregada neste trabalho tem caráter qualitativa, inspirada na pesquisa de Bender Filho (2014), que calculou índices de produção e de produtividade para analisar o progresso e a conduta da indústria brasileira e dos estados de São Paulo, Rio de Janeiro, Minas Gerais, Paraná, Rio Grande do Sul e Santa Catarina, entre os anos de 1996 a 2010. 
Para tal serão aplicados quatro índices de produção e de produtividade industrial, a fim de verificar o comportamento e o desenvolvimento industrial paranaense no período de 2004 a 2014, comparando com o Brasil. Em síntese os dados utilizados serão: Valor da Transformação Industrial (VTI), Pessoal Ocupado (PO), Produto Interno Bruto (PIB), Valor Bruto da Produção Industrial (VBPI). A fonte de dados é a Pesquisa Industrial Anual (PIA) do Instituto Brasileiro de Geografia e Estatística (IBGE), cujo recorte temporal se define entre 2004 e 2014 por permitir a visualização da evolução e o comportamento da indústria paranaense ao longo de uma década.

Cabe aqui esclarecer que o IBGE (2016) define VBPI como somatório das vendas de produtos, serviços e combinações dos estoques das indústrias. Estão inclusos produtos já produzidos, que ainda estão em elaboração e que são produzidos pelo ativo imobilizado próprio. A definição de VTI, é simplesmente o VBTI deduzido dos custos operacionais.

O primeiro indicador será calculado pela razão entre VTI e o VBPI do estado, que expressa a densidade industrial (VTI/VBPI) e cuja finalidade é demonstrar o quanto é especializado o setor. Carneiro (2008) aponta que a especialização facilita a inovação por meio dos efeitos de aprendizagem, que são as experiências acumuladas pelo exercício da atividade. $O$ segundo indicador representa a composição setorial, que indica a participação relativa do VTI (VTI-CS5) dos cinco maiores setores da economia regional à proporção do VTI total da indústria. O objetivo de analisar este indicador é visualizar a parcela de produção composta pelos cinco maiores setores da indústria. Quanto maior o nível, maior é o adensamento industrial. No entanto, para melhor compreensão do indicador, necessita-se verificar o nível de tecnologia empregada por estes setores. De acordo com as teorias de Furtado (1979) e Stiglitz e Walsh (2003), quanto maior o nível de capital empregados na indústria, maior será o nível de produção e produtividade da indústria. Sendo assim, pode-se compreender que quanto maior a tecnologia empregada por estes cinco maiores setores, maior é a propensão a inovar e de aumentar a produtividade.

O terceiro indicador é da produtividade industrial em que o cálculo se realiza pela razão entre o VTI e o Pessoal Ocupada na indústria (PO), que é um reflexo da ação do produto por cada trabalhador. Através dele é possível identificar o nível de renda gerada por cada trabalhador do complexo industrial. São vários fatores atrelados a este indicador, como por exemplo, nível de escolaridade, nível de capital investido por operário, salário, entre outros. O quarto indicador é a proporção do VTI sobre o PIB. Aponta o quanto a indústria representa para a economia, o nível de maturidade e de desenvolvimento. Em conjunto com os demais indicadores, permite uma melhor visualização da interação dos diversos aspectos socioeconômicos.

Serão coletados e apresentados dados sobre inovação industriais no estado e no Brasil, em que será realizada uma análise qualitativa e empírica sobre as relações entre os determinantes de produtividade e as evidências que os índices apontam. O Quadro 2 tem como objetivo simplificar a metodologia que será empregada, facilitando a visualização do cálculo dos indicadores. 
Quadro 1- Indicadores de Produtividade

\begin{tabular}{|l|l|l|}
\hline \multicolumn{1}{|c|}{ Indicador } & \multicolumn{1}{|c|}{ Relação } \\
\hline 1 & $\begin{array}{l}\text { Densidade industrial: Razão entre Valor de Transformação } \\
\text { Industrial e o Valor Bruto da Produção Industrial do Estado }\end{array}$ & VTI/VBPI \\
\hline 2 & $\begin{array}{l}\text { Composição setorial: Participação relativa do VTI dos cinco } \\
\text { maiores setores da economia regional como proporção do VTI } \\
\text { total da indústria }\end{array}$ & VTI-CS5/VTI \\
\hline 3 & $\begin{array}{l}\text { Produtividade industrial: Razão entre o Valor de Transformação } \\
\text { Industrial do Estado e a População Ocupada na Indústria no } \\
\text { Estado }\end{array}$ & VTI/PO \\
\hline 4 & $\begin{array}{l}\text { Valor de Transformação Industrial como proporção do produto } \\
\text { agregado estadual }\end{array}$ & VTI/PIB \\
\hline
\end{tabular}

Fonte: Adaptado de Bender Filho (2014).

É importante ressaltar que os dados foram devidamente deflacionados, para que as relações entre as variáveis possam ser analisadas através de valores reais. Para tal, foi utilizado o Índice Geral de Preços - Disponibilidade Interna - (IGP-DI) acumulado, medido pela Fundação Getúlio Vargas (FGV).

Deste modo, para a construção dos indicadores de densidade industrial, produtividade industrial e valor da transformação industrial como proporção do PIB, foram captados o VTI e VBPI da base de dados do IBGE, deflacionados para o ano base de 2014 e calculados a razão conforme apresentados no Quadro 1. Para a construção do indicador de composição setorial, foram captados dados dos cinco setores que apresentaram os cinco maiores VTI, e calculado a razão da soma do VTI dos cinco maiores setores pelo VTI total do setor industrial para cada ano do período analisado. Ressaltando que foram calculados os quatro indicadores para o cenário nacional e estadual. Sendo assim, na próxima seção os resultados serão apresentados em formas de gráficos e analisados.

\section{RESULTADOS E DISCUSSÕES}

O gráfico 1 apresenta dados do índice de adensamento industrial. Verifica-se que ao longo do período houve crescente aumento deste indicador, em que a partir de 2012 passam a ocorrer oscilações tendentes a diminuição.

Verifica-se, no Gráfico 1 a evolução do adensamento industrial do estado, abaixo do nível nacional, com um crescimento em torno de 5 pontos percentuais entre 2004 a 2011. Entretanto, rapidamente observa-se a perda de 3 pontos percentuais, considerando os anos de 2011 e 2012. Em relação à teoria de Porter (1989), em que o mundo globalizado exige constante especialização na produção com o intuito de usufruir das vantagens comparativas que depois do pico atingido em 2011, a tendência dos anos seguintes foi de queda no índice. Neste caso, verifica-se a questão dos custos, em que a especialização tende a reduzi-los por meio dos benefícios auferidos pelos retornos de escala, e que por sinal, os dados relatados mostram aumento. Sendo assim, constata-se que a indústria paranaense ainda não apresenta indícios de maturidade suficiente para atingir maiores níveis de competitividade, pois nos últimos anos tem apresentado queda de densidade industrial, um comportamento que refuta a indicação de Porter (1989). Sendo assim, constata-se que a indústria paranaense ainda não apresenta 
indícios de maturidade suficiente para atingir maiores níveis de competitividade, tal que, quanto maior o adensamento industrial, maior a probabilidade de inovar, como descrito por Carneiro (2008). Para Schumpeter (1988), a capacidade de inovação está atrelada a grandes organizações, que ao produzirem em larga escala podem utilizar com mais eficiência os recursos.

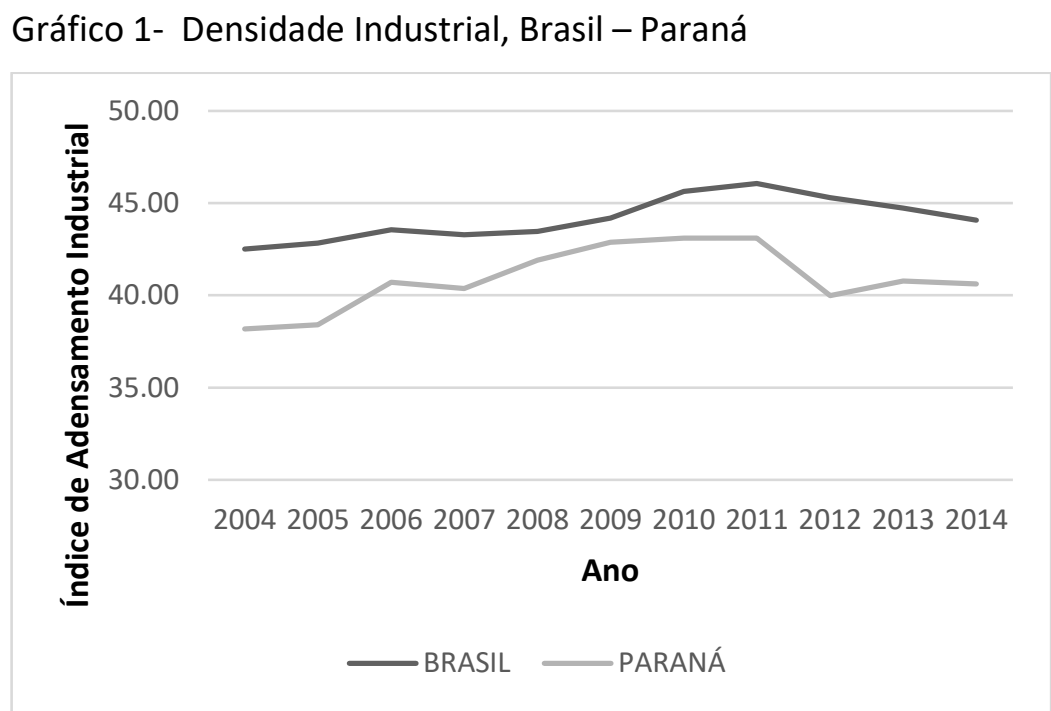

Fonte: Autoria própria (2018).

Ao comparar o cenário estadual com o nacional, os resultados obtidos indicam a mesma tendência para ambos, já que as indústrias alimentícias e fabricação de veículos automotores, reboques e carrocerias são os setores com maior responsabilidade por esta transformação no estado do Paraná. Já no Brasil, além da indústria de alimentos a fabricação de coque, de produtos derivados do petróleo e de biocombustíveis, colocam-se à frente do setor automobilístico. Entretanto, no geral, concentram-se os mesmos setores para ambas as esferas, com exceção do intervalo entre os anos de 2012 e 2014, em que a nível nacional, há maior propensão da indústria extrativa de minerais metálicos.

Pode-se relacionar o realce da indústria automobilística aos esforços de atração deste setor nos anos 1990, ao que Trintin (2006), Sesso Filho et al. (2004) e Nojima (2002) apontaram que o estado usou de incentivos fiscais permitiram a consolidação deste setor no estado. Além disso, a ação conjunta com à boa condição de infraestrutura, potencial de P\&D impulsionada pela presença de universidades, além da estratégia de localização para negociação com o Mercosul, permitiram a consolidação deste setor no estado.

De acordo com Bender Filho (2014), conforme também é possível identificar no gráfico, no caso do índice de adensamento brasileiro, há disposição de recuperação a partir de 2008 seguindo até 2011, onde novamente entra em declínio. Cano (2012) afirma que, inusitadamente, isto ocorre em ano de recessão, e que possivelmente, a explicação deve-se ao alto desempenho de setores de oligopólios. Neste ponto, verifica-se a tendência estadual com o mesmo comportamento.

Visualiza-se no gráfico 2 a composição dos cinco maiores setores em relação ao total da produção industrial. 
Gráfico 2: Nível de Composição Setorial (\%) Brasil- Paraná.

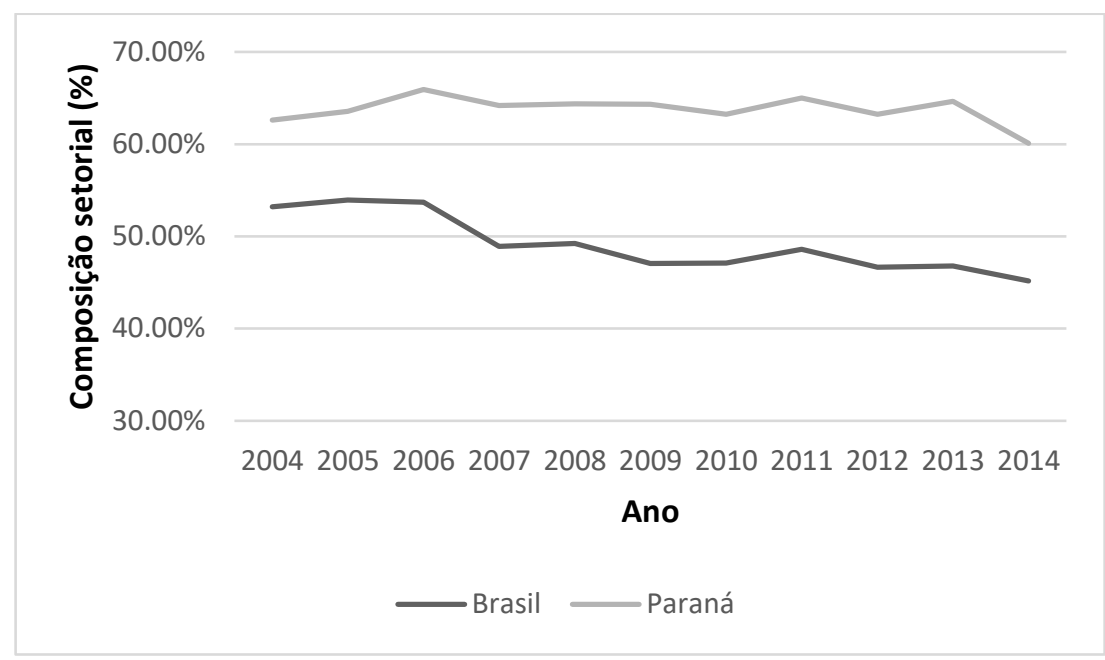

Fonte: Autoria própria (2018).

No período analisado, o comportamento do indicador de composição setorial do Paraná é quase que regular, variando entre $60 \%$ e $66 \%$. Os pontos de maior variação estão em 2006 e 2014, aos quais retratam o maior e menor nível de composição setorial, respectivamente. Verifica -se que o indicador de composição setorial paranaense está acima do Brasil. Sesso Filho et al. (2004) e Trintin (2006) justificam que a composição setorial superior se deve aos esforços do governo estadual através de incentivos fiscais dados à indústria automobilística e a ascensão da indústria extrativa nos últimos anos. Ressalta-se que o governo federal também deu incentivos ao setor automobilístico. No entanto, o diferencial para este setor no âmbito estadual é a boa localização de exportação para os países do Mercosul, conforme aponta Trintin (2006). Entretanto, numa investigação mais detalhada, constata-se que no âmbito estadual o setor de alimentos manteve-se ao longo do período como o mais expressivo, cujo crescimento foi superior a $200 \%$ no VTI. O setor de fabricação de coques e derivados do petróleo manteve crescimento até o ano de 2011, após este período entrou em declínio. O setor químico manteve-se até em 2009 com VTI quase constante e, com exceção de 2008 e 2011, esteve entre os cinco setores mais importantes. A partir de 2010 alavancou crescimento ininterrupto. Conforme dados do IBGE (2016), outro setor que apresentou crescimento contínuo foi o de veículos automotores, reboques e carrocerias. A taxa de crescimento foi superior a 300\% em 2013 em relação a 2004. Já o setor de máquinas e equipamentos passou por um processo de declínio do VTI, para logo após variar entre altos e baixos, em que a sequência contínua de crescimento ocorre somente entre o período de 2011-2013.

É importante ressaltar que a indústria alimentícia não contribui fortemente na inserção de novas tecnologias, pois segundo Nojima (2002), este tipo de indústria exige menores gastos com P\&D e possui escala de produção inferior à de outros setores, e que apesar de alguns setores como o químico, de veículos automotores, reboques e carrocerias contribuírem efetivamente neste ponto de tecnologias, os dados estão apontando detrimento destes setores em favor da ascensão de outros setores que utilizam pouca tecnologia, como exemplo cita-se o próprio setor de alimentos, de madeira e de papel e celulose. 
A análise gráfica permite inferir que há uma grande diferença quanto à composição setorial, mas os resultados obtidos apontam que os setores que se sobressaem como maiores geradores de VTI a nível estadual são basicamente os mesmos a nível nacional. No entanto, a diferença se aplica a partir de 2011, em que os dados evidenciam o impulso da indústria extrativa brasileira, com destaque para os setores de extração de minerais metálicos e de petróleo e gás natural. Para Nojima (2002) os setores de extração fazem parte do grupo de indústrias fornecedoras, produtoras de commodities.

Cabe, portanto, observar que a tendência de especialização em indústria de do grupo tradicional pode ser um limitador para o crescimento produtivo e consequentemente ao desenvolvimento econômico e, que tanto no âmbito nacional quanto estadual, há maior propensão ao crescimento de indústrias de baixa tecnologia. Quanto ao que pode ser constatado através do indicador de composição setorial, esta inversão de tendência de geração de VTI entre as indústrias do grupo tecnológico e grupo tradicional, coincide com resultado apontados por Oliveira (2001), Migliorini (2006) e Macedo (2009). Como este indicador reflete a propensão a inovar e aumentar a produtividade, espera-se uma queda do indicador de produtividade, o qual será analisado na sequência. É importante definir, segundo Nojima (2002), que grupo tecnológico abrange as indústrias que possuem uso intensivo e são difusoras de tecnologia, enquanto que o grupo tradicional abrange as indústrias que possuem menores gastos com $P \& D$ e escala de produção inferiores a outros setores.

O terceiro índice aponta o nível de produtividade do trabalho, ao qual se mede pela relação entre VTI e pessoal ocupado, afim de identificar a geração da renda por trabalhador no setor industrial. 0 Gráfico 3 apresenta o comportamento do indicador produtividade.

Gráfico 3: Produtividade Industrial, Brasil-Paraná

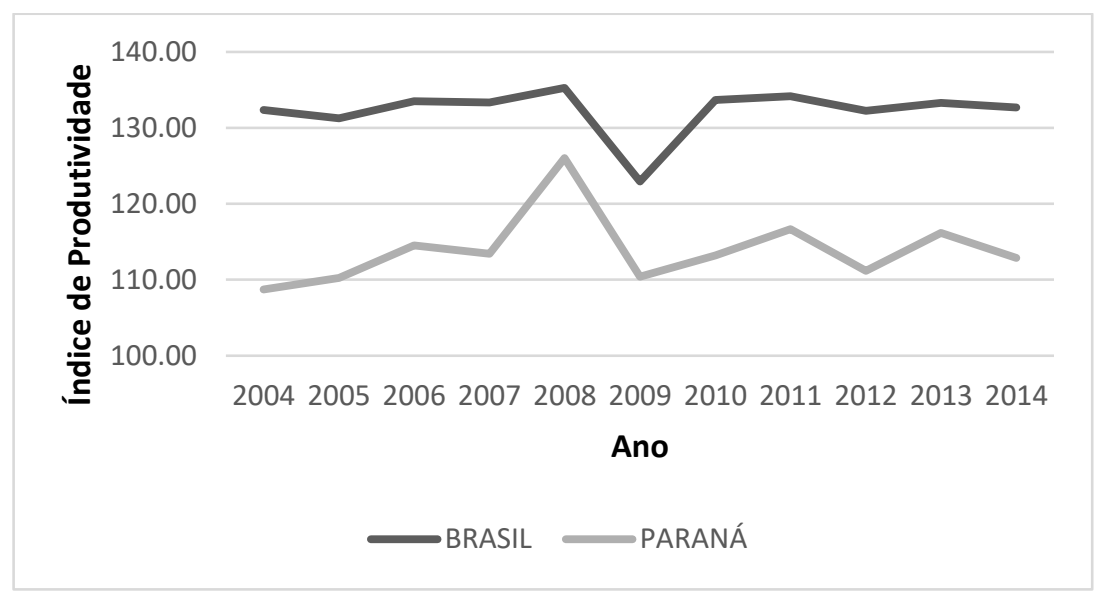

Fonte: Autoria própria (2018).

No Gráfico 3, nota-se que os dados indicam uma tendência mais uniforme da produtividade brasileira ao longo dos anos, com exceção do maior pico registrado em 2008 e logo após uma brusca queda em 2009, mantendo posteriormente oscilações não tão acentuadas. Ao analisar o Paraná, observa-se oscilações mais acentuadas. Para Bender Filho (2014), a explicação possível a este comportamento da produtividade, ocorre devido a maior variação de empregos na indústria do que do VTI. 
A nível de comparação com outros estados, considerando a pesquisa de Bender Filho (2014), a produtividade industrial do Paraná está num nível médio, abaixo de estados como Rio de Janeiro e São Paulo e acima de estados como Rio Grande do Sul e Santa Catarina, sendo esses os estados com maior desenvolvimento do país. Como é possível visualizar, em comparação, a nível nacional, o estado se mantém com produtividade abaixo da média do país. No entanto, este indicador demonstra a ação do produto por cada trabalhador, e os resultados obtidos apontam que quantidade de trabalhadores continuou em crescimento, o que indica uma queda no nível de investimento do fator capital por trabalhador. Isso pode refletir, com base nos argumentos de Stiglitz e Walsh (2003), um grande empecilho ao fomento de mudanças tecnológicas.

Dada relação da produtividade com variáveis importantes, como capital humano, P\&D e inovação, verifica-se que o Paraná, a partir de 2004, realizou "...um investimento volumoso de recursos" nas universidades e faculdades públicas estaduais (IPARDES, 2010, p. 24). No entanto, dados do Ministério da Ciência, Tecnologia e Inovação (2016) e da FIEP (2016) apontam que, em comparação a nível de Brasil, o estado do Paraná possui um baixo índice de população com ensino superior e de população com ensino médio, aproximadamente $9 \%$ e $50 \%$, respectivamente. Neste caso, identifica-se a soma de dois fatores que afetam a produtividade no estado, são eles: uma possível queda o nível de investimento de fator capital por trabalhador; e a situação atual do capital humano não tão capacitado quanto indicado pela literatura para o desenvolvimento econômico.

Dentre as implicações, cita-se a teoria de Romer (1980), Stiglitz e Walsh (2003) e Freeman e Soete (2008), que apontam que o estoque de ideias, treinamento e aperfeiçoamento da mão de obra constituem parte do conjunto de elementos fomentadores de inovação e produtividade. Visto que Nelson (2006) destaca a importância da incorporação rápida de novas tecnologias advindas do estrangeiro, afim de minimizar o atraso e que Santos (2012) destaca a baixa participação de profissionais voltados às atividades de inovação.

Os dados também apontam a crescente absorção de trabalhadores pela indústria paranaense. Segundo Stiglitz e Walsh (2003), para que haja aumento da produtividade, é necessário que ocorra a redução do emprego, no sentido de que os benefícios são maiores para a economia como um todo, diferentemente do que os dados apontaram. Neste aspecto Furtado (1979) evidencia que um aumento da produtividade torna o bem mais barato, melhora os salários e o consumo, levando ao desenvolvimento econômico.

É importante ressaltar que, na literatura consultada, as pesquisas de Arbache (2005), Silva e Avellar (2015) e Nassif (2008), demonstraram expressivos sinais de que a inovação afeta positivamente a produtividade. Considerando que o Paraná é dividido geograficamente em dez mesorregiões, Rigitano, Nascimento e Camara (2013) apontam as mesorregiões Metropolitana de Curitiba, Oeste e Centro Oriental como as que possuem os maiores índices de PTF, regiões que por sua vez, coincidem com a classificação do Ipardes (2006) como sendo as mais dinâmicas. Não obstante, Suzuki Júnior (2010) completa indicando a conjuntura como fator que empurra a produtividade estadual para baixos níveis.

O último indicador, apresentado no gráfico 4, aponta o VTI como proporção do PIB, que revela a geração de renda da indústria no Brasil e no Paraná. 
Gráfico 4- Participação do Valor de Transformação Industrial no PIB (\%)

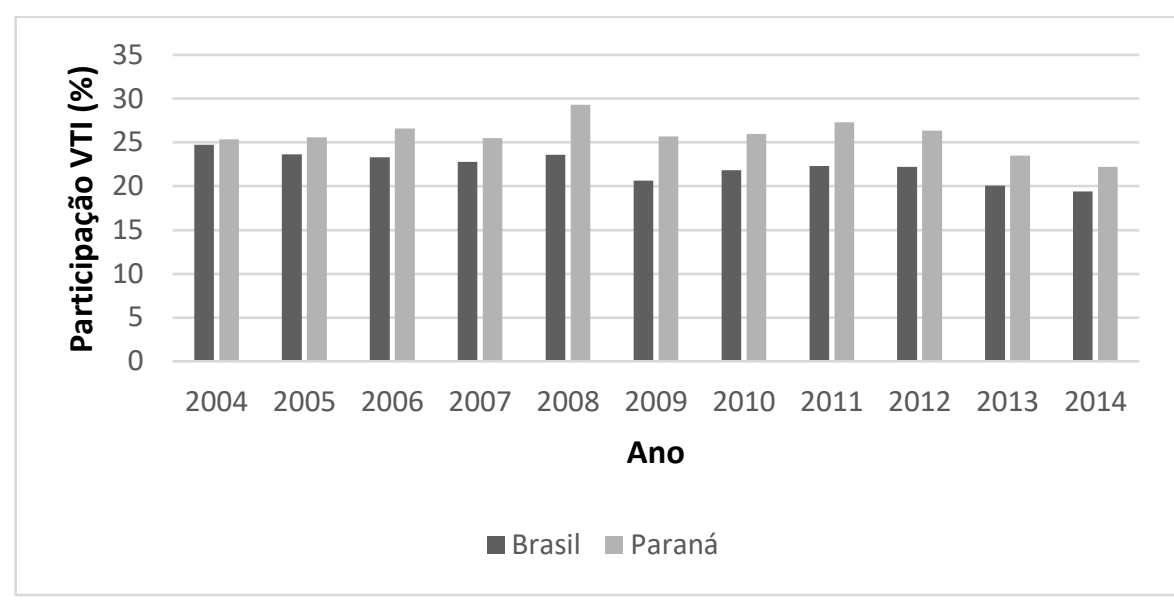

Fonte: Resultados da Pesquisa.

Verifica-se que o maior pico do índice de participação do VTI sobre o PIB foi em 2008, seguido de queda e recuperação em a partir de 2010. Um estudo publicado pelo Instituto de Estudos para o Desenvolvimento Industrial (IEDI) em 2011, aponta justamente que, para a recuperação da indústria nacional a partir de 2010, a explicação está pautada na utilização de ocupação de fatores ociosos na economia, que por sua vez foi causada pela queda expressiva da produção industrial em torno de 7,4\%. Todavia, os dados apresentados indicam que o custo do trabalho, neste período, manteve-se em alta, chegando a uma variação positiva de $4,9 \%$. Entretanto, a nível nacional, percebe-se redução de $5 \%$ no pessoal ocupado na indústria em 2009, o que não se aplica ao âmbito estadual, cujo dados demonstram crescimento do pessoal ocupado.

O que se verifica é o adensamento com perspectiva de queda nos últimos anos e ainda abaixo do grau do Brasil, que como já foi discutido, mede a capacidade de inovação, ou seja, quanto mais adensado, maior a probabilidade a inovar. A composição setorial, embora mais concentrada do que a composição ao nível nacional, tem grande base pautada na indústria de alimentos, que devido ao baixo uso de tecnologias quase não possui tendências de inovação. A alavancagem da indústria automobilística, que incorpora mais tecnologia, apresenta tendência de queda. Suzuki Junior (2010) aponta que esta tendência de não consolidação de indústrias de alta tecnologia está atrelada ao potencial agropecuário, cuja caracterização realizada pelo IPARDES (2010) demonstra de forma clara a ampla difusão do setor nas diversas regiões do estado. Neste sentido, Santos (2012), evidenciou que a inovação não é uma estratégia de longo prazo das empresas brasileiras, por isso conta com poucos dispêndios em na criação de produtos que produzam mudanças de alto impacto.

De qualquer forma, estes índices interferem na questão de produtividade, uma vez que seu impulso é dado pela inserção de novas tecnologias, especialização do capital humano e da produção, P\&D, obtenção de vantagens de custos, entre outros. Entretanto, o que se observa é uma inclinação de não potencialização destes elementos fundamentais, visto que a alta participação do VTI na proporção do PIB é corroborada pela absorção da mão de obra, não indica, portanto, a elevação da renda pela a incorporação de inovações. 
Em análise global dos dados, há indícios que o estado do Paraná possui significativa representatividade do seu aglomerado industrial para o Brasil, no entanto, ainda é possível observar a insuficiência no seu desenvolvimento medido por seus indicadores, principalmente, o de produtividade. Entende-se, portanto, que o ambiente macroeconômico nacional se mostra propício ao desenvolvimento de tais indicadores, uma vez que a dinâmica nacional mostrou melhores indicadores de desenvolvimento industrial. Suzuki Junior (2010) enfatiza que no cenário nacional as indústrias de commodities registram resultados superiores a outras indústrias que geram maior adição de valor, tais como, as indústrias têxtil, de madeira e de vestuário. Porém, o estado de São Paulo que concentra indústrias com maior uso de tecnologias, auxiliou na manutenção do indicador de produtividade superior ao do Paraná No cenário estadual, o autor ressalta que a indústria alimentícia apresentou crescimento, o que de certa forma limitou o aumento da produtividade no estado.

O ponto de partida, conforme a concordância da literatura, dá-se principalmente pela qualificação dos recursos humanos, ao que Porter (1989) faz questão de enfatizar sendo uma medida praticamente simples, alcançável por qualquer nação. A falta de capacitação de grande parte da população tem afetado os indicadores de forma negativa, com alta absorção de mão de obra, baixo registro de patentes, baixos dispêndios com P\&D e alta dos custos, seguindo ao lado contrário do que defende a literatura mostrada.

Levando em consideração o atual cenário econômico do Paraná, pode-se entender que as políticas públicas não se mostram eficientes para instigar o aperfeiçoamento da mão de obra. Neste sentido, dados do Ipardes (2017) apontam que embora tenha sido dispendido recursos estaduais na expansão do ensino superior, em cursos de graduação e pós-graduação, inclusive com desconcentração geográfica, ainda há contribuição desigual da base técnicocientifica no território paranaense. Além disso, as regiões de Curitiba e seus arredores, eixo territorial Londrina-Maringá, e vértice da região de Cascavel, Toledo e Foz do Iguaçu, apresentam diferenciais de competitividade oriundas das melhores condições em atrair a articular projetos cooperativos, que envolvem o governo, empresas e instituições de ensino e pesquisa. Ou seja, possivelmente os mecanismos econômicos usados não promovem as condições necessárias para a formação de um ambiente propício a inovação, especialização, e por consequência, o aumento da produtividade. Mostram, portanto, a necessidade de revisão de tais políticas.

\section{CONSIDERAÇÕES FINAIS}

Schumpeter é o precursor dos estudos da inovação e seu impacto sobre o crescimento e desenvolvimento econômico. $\mathrm{O}$ autor apontou que as grandes empresas possuem vantagens diante das pequenas, ao serem capazes de utilizar mais eficientemente os recursos, incrementando a produtividade como reflexo deste processo. É importante ressaltar que o foco principal de Schumpeter são os meios de produção, com claro objetivo de redução de custos para aumentar os lucros. Posteriormente, os seguidores da teoria schumpeteriana, chamados neoschumpeterianos, identificaram a P\&D como grande chave para a geração e disseminação de inovações. 
Mais tarde, considerando a institucionalização da P\&D e o progressivo reconhecimento das incertezas, a literatura trata os efeitos de aprendizagem como fundamento essencial, a ponto de compreender que os custos só são tão importantes quando não há aperfeiçoamento da mão de obra. Sendo assim, a variável chave no fomento de inovação passa a ser o capital humano, a ponto de relacioná-la com a capacidade de assimilação de tecnologias do estrangeiro, em que os impactos podem serem vistos no aumento do PIB e da produtividade.

Ao identificar na literatura os determinantes da inovação e produtividade, constatou-se o sentido a esta constante busca, em que o principal objetivo é o desenvolvimento econômico. A produtividade pode ser vista, como uma variável inversamente proporcional ao número de trabalhadores, a ponto de que a desocupação de mão de obra represente benefícios maiores para a economia do que malefícios. Desta maneira, a relação passa a ser suficientemente ampla, cabendo discussões em pontos microeconômicos, macroeconômicos, e das conjunturas que são inseridas na economia. Deste modo, a produtividade e inovação são interdependentes e juntas desencadeiam virtuosos efeitos econômicos, pois promovem melhor aproveitamento dos recursos, sejam eles de produção e/ou humanos.

Em síntese, notou-se a importância relativa do Paraná para a economia brasileira, ao qual apresenta o quinto maior PIB, com expressiva representatividade nas exportações, no registro de patentes, entre outros fatores. Constata-se na sua história a contínua busca pela industrialização, tanto com dispêndios em investimentos de infraestrutura, uso de subsídios fiscais e visão de localização estratégica na negociação com os países da América latina, via Mercosul. Além disso, contando com a presença de universidades que são essenciais na realização de P\&D.

A realização deste trabalho permitiu a identificação dos desempenhos dos indicadores das indústrias do Paraná ao longo do período entre 2004 a 2014, a fim de verificar a relação entre o desempenho da dinâmica industrial e os determinantes de inovação e produtividade, comparado ao Brasil.

Verificou-se que o Paraná apresenta dois dos indicadores abaixo do nível nacional, sendo eles o de produtividade e de adensamento industrial, sendo que o primeiro indica a propensão a inovar, e o segundo a relação renda por trabalhador. Ou seja, há evidências que indicam insuficiência na especialização e aperfeiçoamento do capital humano. Quanto aos demais indicadores, nível de composição setorial e participação do VTI em proporção do PIB, embora se apresentem acima do nível nacional, possuem tendência em conformidade com a literatura, que é a especialização. No entanto, a indústria alimentícia, setor que mais gera VTI, utiliza pouca tecnologia e, por consequência, possui baixa propensão a inovar. Tal fato, combinado com o aumento crescente na absorção de mão de obra, provoca queda da renda por trabalhador, resultando em um efeito negativo para aumento da competitividade industrial.

Desta forma, pode-se inferir que há evidências de baixo aproveitamento dos determinantes de inovação e produtividade no estado do Paraná. Ao comparar a nível de Brasil, entende-se que existem espaços a serem considerados mais eficazes na utilização destes recursos. Neste ponto, refuta-se a hipótese de que, baseado pela boa representatividade do setor a nível nacional e aspectos favoráveis para o comércio exterior, o estado apresentaria bons indicadores de 
produtividade do setor industrial. Sendo assim, trabalhos futuros podem contribuir ao buscar analisar profundamente os gargalos que impedem a potencialização destes determinantes. Indica-se a utilização de métodos que possibilitem a verificação de quais elementos essenciais são mais desprovidos e quais políticas podem ser utilizadas para a modificação do cenário da indústria paranaense aqui exposto.

Dada a análise baseada na observação de dados e cálculo de indicadores, verifica-se a importância de complementar as discussões a partir de análise mais detalhada sobre o assunto. Podem ainda, serem analisadas as políticas industriais praticadas em ambas as esferas, políticas voltadas a inovação, educação, dentre outros mais específicos que moldaram a economia nacional e estadual. 


\title{
Industrial Dynamics and Innovation in the State of Paraná between 2004 and 2014
}

\begin{abstract}
In the process of growth and economic development, the participation of secondary sector and their respective level of productivity play an important role. In this context, the objective of this research was to analyze the index of productivity and to verify the Paranaense industry performance. The employed methodology was to calculate the production and productivity industrial indices, in the period of 2004 to 2014, and to compare with the national level from the innovation and productivity theorists' views. The results indicated that the industrial densification turn up as perspective of a decline, the sectorial composition is guided in the food industry and the value of industrial transformation as proportion of PIB turn up above the national average, but with intensive use of labor. Stand out also the low specialization of Human Capital results in an ambient with low propensity to innovate and, consequently, low productivity. We suggest that the key elements of innovation and productivity are not potentially used to achieve higher rates of economic growth in Paraná.
\end{abstract}

KEYWORDS: Productivity. Innovation. Paraná 
ARBACHE, Jorge S. Inovações tecnológicas e exportações afetam o tamanho e a produtividade das firmas manufatureiras? Evidências para o Brasil. In: João Alberto De Negri e Mário Sérgio Salerno. (Org.). Inovações, padrões tecnológicos e desempenho das firmas industriais brasileiras. Brasília: IPEA, 2005, p. 477-510. Disponível em: <http://www.ipea.gov.br/portal/images/stories/PDFs/livros/Inovacao_Padroes_t ecnologicos_e_desempenho.pdf> Acesso em: 08 maio 2016.

BENDER FILHO, Reisoli. Dinâmica industrial: evidências para o Brasil e para as regiões sudeste e sul. In: ENCONTRO DE ECONOMIA GAÚCHA, 7, 2014, Porto Alegre. Anais eletrônicos... Porto Alegre, 2014. Disponível em: < http://www.fee.rs.gov.br/wp-content/uploads/2014/05/201405237eeg-mesa3dinamicaindustrial.pdf> Acesso em: 29 ago. 2016.

COSTA, Achyles B. O desenvolvimento econômico na visão de Schumpeter. Caderno IHU Idéias, São Leopoldo, v.4, n.47, 2006. Disponível em: http://sinop.unemat.br/site_antigo/prof/foto_p_downloads/fot_7471schumpete b_pob_costa_pdff. Acesso em: 14 jun. 2016.

CASTAGNA, Annemarlen G.; TIEPOLO, Gerson; RIBEIRO, Maria de F. S.; BRACARENSE, Paulo. Crise Energética e Planejamento Energético no Paraná. Revista Paranaense de Desenvolvimento. Curitiba, v. 37, n. 130, p.63-81, jan./jun. 2016. (versão online) Disponível em: < http://www.ipardes.pr.gov.br/ojs/index.php/revistaparanaense/article/view/763 /0> Acesso em: 23 out. 2016.

CARNEIRO, Ricardo. Impasses do desenvolvimento brasileiro: a questão produtiva. Texto para discussão. Instituto de Economia/UNICAMP, Campinas, n. 153, nov. 2008. (versão online) Disponível em: $<$ www.eco.unicamp.br/docprod/downarq.php?id=1783\&tp=a> Acesso em: 12/10/2016.

DOSI, Giovanni. Mudança Técnica e Transformação Industrial. Campinas: Unicamp, 2006.

FIEP (FEDERAÇÃO DAS INDÚSTRIAS DO ESTADO DO PARANÁ). Panorama Industrial do Paraná, 2016. Curitiba, 2016.

FREEMAN, Chris; SOETE, Luc. A Economia da Inovação Industrial. Campinas: Unicamp, 2008. 
GALEANO, Edileuza A.V.; WANDERLEY, Lívio A. Produtividade industrial do trabalho e intensidade tecnológica nas regiões do Brasil: uma análise regional e setorial para o período 1996-2007. Planejamento e Políticas Públicas, n. 40, jan. /jun. 2013. (versão online) Disponível em < http://www.ipea.gov.br/ppp/index.php/PPP/article/view/370> Acesso em: 22 abr. 2016.

INSTITUTO BRASILEIRO DE GEOGRAFIA E ESTATÍ́STICA (IBGE). Sidra: Pesquisa Industrial Anual (PIA). Disponível em:< http://www.sidra.ibge.gov.br> Acesso: set. 2016.

INSTITUTO DE ESTUDOS PARA O DESENVOLVIMENTO INDUSTRIAL - IEDI. Análise IEDI- Recuperação da produtividade em 2010 e as perspectivas. São Paulo: IEDI, 2011.

Disponível

em:

http://www.iedi.org.br/artigos/top/analise/analise_iedi_20110207_industria_rec uperacao_da_produtividade_em_2010_e_as_perspectivas.html> Acesso em: 13 out. 2016.

INSTITUTO PARANAENSE DE DESENVOLVIMENTO ECONÔMICO E SOCIALIPARDES. Os Vários Paranás: Identificação de espacialidades socioeconômico institucionais como subsídio a políticas de desenvolvimento regional. Curitiba: IPARDES, 2006.

INSTITUTO PARANAENSE DE DESENVOLVIMENTO ECONÔMICO E SOCIALIPARDES. Os Vários Paranás: as espacialidades socioeconômico -institucionais no período de 2003 a 2015. Curitiba: IPARDES, 2017. Disponível em: <http://www.ipardes.gov.br/biblioteca/docs/varios_paranas_relatorio_2017.pdf > Acesso em: 12 dez. 2017.

INSTITUTO PARANAENSE DE DESENVOLVIMENTO ECONÔMICO E SOCIALIPARDES. O Paraná na primeira década do século XXI. Nota técnica $n^{\circ} 20$. Curitiba, 2010.

JONES, Charles I. Introdução à Teoria do Crescimento Econômico. Trad.: Maria José Cyhlar Monteiro. Rio de Janeiro: Elsevier, 2000.

KIM, Linsu. Da Imitação à inovação. Trad. Maria Paula G.D. Rocha. Campinas: Unicamp, 2005.

MACEDO, Mariano de M. Notas sobre a relação estado e sociedade no Paraná: uma breve digressão para o período 1853-1965. Revista Paranaense de Desenvolvimento, Curitiba, n.116, p.117-137, jan./jun. 2009 Disponível em : <http://www.ipardes.gov.br/ojs/index.php/revistaparanaense/article/view/317/ 267> Acesso em 28 ago. 2016. 
MIGLIORINI, Sonia M, dos S. Indústria Paranaense: Formação, transformação econômica a partir da década de 1960 e distribuição espacial da indústria no início do século XXI. Revista Eletrônica Geografar, Curitiba, v.1, n.1, p.62-80, jul./dez., 2006.2 Disponível em:

http://revistas.ufpr.br/geografar/article/view/6843> Acesso em: 27 ago. 2016.

MINISTÉRIO DA CIÊNCIA, TECNOLOGIA, INOVAÇÃO E COMUNICAÇÕES. Banco de variáveis CT\&l. Disponível em <http://www.mct.gov.br/index.php/content/view/2051/_b_i_Producao_cientifi ca_b_i_.html> Acesso em: 02 set. 2016.

NASSIF, André. Há evidências de desindustrialização no Brasil? Revista de Economia Política. São Paulo, V.28, n.1, p. 72 a 96, 2008. Versão online disponível em: $\quad$ http://www.scielo.br/scielo.php?script=sci_arttext\&pid=S010131572008000100004. Acesso em: 05 set. 2016.

NELSON, Richard R. As Fontes do Crescimento Econômico. Campinas, SP: UNICAMP, 2006.

NOJIMA, Daniel. Crescimento e reestruturação industrial do Paraná- 1985/2000. Revista Paranaense de Desenvolvimento. Curitiba, n.103, p.23-43, jul./dez. 2002. Disponível em: $<$ http://www.ipardes.pr.gov.br/ojs/index.php/revistaparanaense/article/view/20 1> Acesso em: 28/08/2016.

OCDE, Organização para a Cooperação e o Desenvolvimento Econômico. Manual de Oslo: Diretrizes para coleta e interpretação de dados sobre Inovação. $3^{\circ}$ edição, Oslo: 1997. Disponível em: < http://www.finep.gov.br/images/apoio-efinanciamento/manualoslo.pdf> Acesso em: 14 ago. 2016.

OLIVEIRA, Dennison de. Urbanização e Industrialização do Paraná. Curitiba: SEED, 2001.

PINHEIRO, Mauricio C. BARBOSA FILHO, Fernando de H. Produtividade e Convergência entre Estados Brasileiros: exercício de decomposição setorial. Economia Aplicada, Ribeirão Preto, v. 15, n. 3, 2011, p. 417-442. (versão online) Disponível em: <http://www.scielo.br/scielo.php?script=sci_arttext\&pid=S141380502011000300004> Acesso em: 22 abr. 2016

PORTER, Michael. A Vantagens Competitiva das Nações. Trad. Waltensir Dutra. $8^{\circ}$ edição. Rio de Janeiro: Campus, 1989. 
RIGITANO, Alisson O.; NASCIMENTO, Sidnei P. do; CAMARA, Marcia R.G. da. Diferenças na produção e produtividade entre as regiões e setores no estado do Paraná. Revista Brasileira de Economia de Empresas, v.13, n.2, 2013. Disponível em <https://portalrevistas.ucb.br/index.php/rbee/article/view/4246> Acesso em: 31 ago. 2016.

SANTOS, David F. L. O perfil da Inovação na Indústria Brasileira. Revista Gestão Industrial, Ponta Grossa, v. 8, n.3, p. 142-163, 2012. Disponível em: <https://periodicos.utfpr.edu.br/revistagi/article/view/1176>. Acesso em: 12 dez. 2016.

SCHUMPETER, Joseph A. A Teoria do Desenvolvimento Econômico. Trad. Maria Sílvia Possas. $3^{\circ}$ ed. São Paulo: Nova Cultural, 1988.

SILVA, Felipe Q. DE AVELLAR, Ana Paula M. P\&D, inovação e produtividade: evidências para empresas industriais brasileiras. In: Encontro Nacional de Economia, 43.:2015, Florianópolis. Anais Eletrônicos... Florianópolis: Costão do Santinho. Artigo. (versão online) Disponível em: < https://www.anpec.org.br/encontro/.../i91f25cde9cc6883c836aabe0b0be74511.pdf> Acesso em: 03 jul. 2016.

SUZUKI JUNIOR, Júlio T. As características do crescimento industrial paranaense. Nota técnica $n^{\circ}$ 5, Curitiba: Ipardes, 2010.

Recebido: 09 jan. 2018

Aprovado: 02 out. 2018

DOI: $10.3895 /$ gi.v14n4.7603

Como citar:

DALLA CORTE, G.; MORAES, M. L. Dinâmica Industrial e Inovação no Estado do Paraná entre 2004 e 2014

R. Gest. Industr., Ponta Grossa, v. 14, n. 4, p. 196-221, out./dez. 2018.

Disponível em: <https://periodicos.utfpr.edu.br/rgi>. Acesso em: XXX.

Correspondência:

Greice Dalla Corte

Rua Uruguai, número 716, Bairro Vila Nova, Francisco Beltrão, Paraná, Brasil. CEP 85605-370.

Direito autoral: Este artigo está licenciado sob os termos da Licença Creative Commons-Atribuição 4.0

Internacional.

\section{(c) (1)}

